\title{
The anxious, the furious, and the annoyed \\ Hidden shame in the academic library
}

n March 2018, my manuscript on library shame was published in College $\&$ Research Libraries. ${ }^{1}$ The paper's focus is library anxiety, but more accurately it is about the shared experience of normal shame for both the librarian and the user. When shame is misidentified as maladaptive behavior by both the librarian and user, it results in alienation or conflict. When shame is identified by the librarian as normal, it strengthens the relationship with the user.

According to scholars who study the shame affect, shame by itself is not a bad thing. The problem is that most of our shame is hidden. ${ }^{2}$ We hide shame behind vague language. When we do use the s-word, it is narrowly defined. For example, library anxiety is nothing more than library shame, or shame about shame, but because our vernacular usage of shame is synonymous with failure or disgrace, the term library shame sounds demoralizing.

Regarding shame, there are no offenders, victims, or institutions to blame. No one is at fault. The smartest, most emotionally intelligent librarians in the world cannot stop shame from occurring in an institution of higher education or in themselves. Shame is an innate affect, one of nine according to affect theory, and it is an essential component in the learning process; therefore, libraries are a natural and healthy place for shame to occur.

Shame regulates our social bonds. When we imagine or perceive a negative evaluation of ourselves through our own eyes or through the eyes of others, we are feeling the shame affect. When we feel powerless, awkward, ridiculed, embarrassed, weird, strange, or humiliated, we are feeling manifestations of normal shame.

\section{Shame's role in the learning process}

When Carol Kuhlthau developed a model of the library research process, she discovered that students felt threatened within seconds of a research project being assigned. ${ }^{3} \mathrm{Ab}-$ sorbing new ideas and information requires an awareness that one's own knowledge is either incorrect or lacking, therefore we must devalue our own knowledge if we are to accept new information. For many people, this threat or devaluation (normal shame) is embraced as a challenge. For others, the feeling is misidentified as incompetence or stupidity, which produces more shame. This is how shame becomes compounded and destructive. We interpret the emotion as a character defect within ourselves (shame-guilt) or we blame something outside ourselves (shame-anger). ${ }^{4}$

Avoidance, anxiety, and resentment are common manifestations of hidden shame. ${ }^{5}$ In the academic library, these shame states

Erin McAfee, retired Rice University user services associate, is a career and technical education instructor at Memorial Early College High School, St. Philips College, email: erin.leslie.mcafee@gmail.com

(c) 2019 Erin McAfee 
can be overwhelming. The library embodies knowledge and learning, so for many, it is ground zero for their shame. Three common manifestations of hidden shame in the library are:

1. The anxious user who is afraid to ask for help because the librarian is perceived as too intimidating or too busy to approach.

2. The high-conflict user who erupts into humiliated fury while disputing the fairness of library policies or procedures.

3. The annoyed information professional who has become synonymous with the librarian stereotype.

\section{The anxious}

Library anxiety, a term devised by Constance Mellon in 1986, is a situation specific, social anxiety that keeps a person in an endless loop of compounded shame. It begins when a person perceives that the library staff will negatively evaluate him for his poor knowledge. The shame worsens when the person realizes that asking questions will expose ignorance. The most ubiquitous example of library anxiety appears in the form of an apology. When a user apologizes to the librarian for asking a question in a serious tone, he is feeling unacknowledged shame.

\section{The furious}

Often referred to as the "difficult customer," the furious library user is experiencing shame that is completely repressed. In 1971, the Yale professor and psychoanalyst Helen B. Lewis published ground-breaking research on unidentified shame. ${ }^{6}$ "Bypassed shame," she said, "is completely denied and felt as a 'wince,' 'blow,' or 'jolt."' When a user feels stupid or treated unfairly, he may bypass these feelings of shame altogether and only experience rage.

\section{The annoyed}

According to psychologists from Tilberg University in the Netherlands, shame can be felt while observing the behavior of others. ${ }^{8}$
Two ways that librarians and library staff can experience vicarious shame are:

1. through identification, e.g., feeling shame (embarrassed/awkward) when a user repeatedly apologizes for needing help, and

2. through an event that reflects negatively on one's social identity, e.g., feeling annoyed when a user's behavior indicates disrespect for the library or library roles.

Feeling embarrassed, awkward, annoyed, or irritated are manifestations of shame that can be felt through the actions of other people.

For example, say a library instructor feels annoyed when a student creates an inordinate amount of interruptions during a class. The annoyance is immediate. The instructor has no conscious thought process about why he is irritated. He just knows the student's behavior is irritating. He will disagree with the notion that he is feeling normal shame, because in our modern society, we interpret shame as a weakness. We disavow the emotion almost entirely, but to feel powerless is to feel normal shame.

The instructor is a competent educator and the student's behavior does not change this fact, but the disruption, within a millisecond, causes a negative self-reflection for the instructor. She must reassess his ability to maintain control of the lesson, hence the shame to her social identity as a teacher.

\section{How to manage shame}

When hidden shame is externalized as annoyance it is evident by one's tone, body language, eye contact, and attitude. Shame is designed by nature to 1) paralyze our positive emotions, 2) make us reflect negatively on ourselves, and 3) isolate us. Shame alienates. To counteract shame, employ its opposite feeling. The opposite of shame is not pride, it is connectedness. When annoyed, instead of measuring a person's perspective as right, 
wrong, good, or bad, view his experience as normal and sane. Attunement is the antidote for shame. ${ }^{9}$

Most important, if feeling irritated or annoyed, attunement for one's own shame response is critical. According to the psychologist Paul Gilbert, compassion is a sensitivity to suffering of the self and others with a deep commitment to try and relieve it. ${ }^{10}$ We typically don't attune to our own suffering when shame stirs a negative reflection of ourselves because we don't identify this feeling as a naturally occurring, negative emotion.

If vicarious shame is detected in an interaction with a user, self-compassion and attunement would sound something like this:

This feeling is disturbing, but it will pass if I allow myself to be human and not blame myself or the user. He seems frustrated and confused. These are both signs of shame. His feelings make sense given that many people feel shame in libraries. He has no idea that these negative feelings are normal. I can let him know in a respectful way that he is making progress.

Discovering hidden shame has been lifechanging for me. In both my work and personal relationships, blame and conflict diminish quickly. Compassion is suddenly accessible. Weakened bonds are strengthened. The goal is not to get rid of it. The goal is to identify it, disempower it with self-compassion, and use it to build better and stronger relationships.

\section{Notes}

1. Erin L. McAfee, "Shame: The Emotional Basis of Library Anxiety," College $\&$ Research Libraries 79, no. 2 (2018): 237-56.

2. Thomas J. Scheff, "The Ubiquity of Hidden Shame in Modernity," Cultural Sociology 8, no. 2 (2014): 134.

3. Carol C. Kuhlthau, "Inside the Search Process: Information Seeking from the User's Perspective," Journal of the American Society for Information Science 42, no. 5 (1991): 361-71.

4. Thomas J. Scheff and Suzanne M. Retzinger, Emotions and Violence: Shame and Rage in Destructive Conflicts (Lexington, Mass.: Lexington Books, 1991), 13.

5. Constance A. Mellon, "Library Anxiety: A Grounded Theory and Its Development," College \& Research Libraries 47, no. 2 (1986): 160-65.

6. Helen B. Lewis, Shame and Guilt in Neurosis (New York: International, 1971).

7. Ibid., 196-97.

8. Stephanie CM Welten, Marcel Zeelenberg, and Seger M. Breugelmans, "Vicarious shame," Cognition \& emotion 26, no. 5 (2012): 836-46.

9. Scheff and Retzinger, Emotions and Violence, 60.

10. Paul Gilbert, Mindful compassion: Using the power of mindfulness and compassion to transform our lives (Hachette UK, 2013). 2

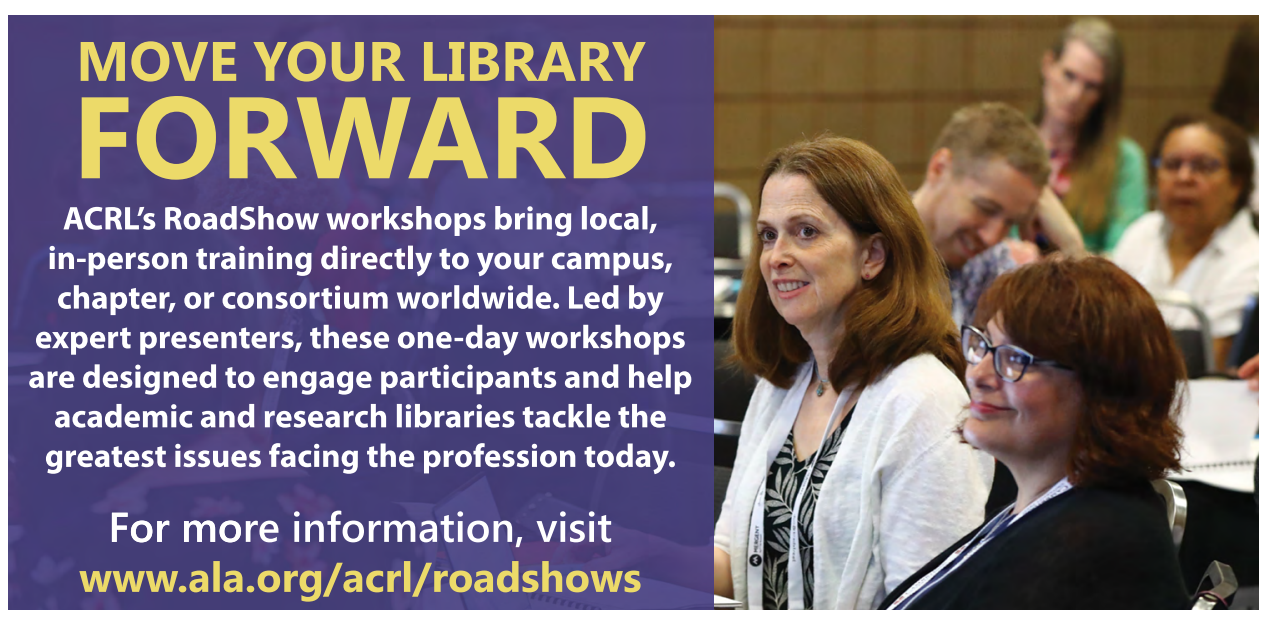

